\title{
Expression of Medicago truncatula Genes Responsive to Nitric Oxide in Pathogenic and Symbiotic Conditions
}

\author{
Alberto Ferrarini, ${ }^{1}$ Matteo De Stefano, ${ }^{1}$ Emmanuel Baudouin, ${ }^{2}$ Chiara Pucciariello, ${ }^{2}$ \\ Annalisa Polverari, ${ }^{3}$ Alain Puppo, ${ }^{2}$ and Massimo Delledonne ${ }^{1}$ \\ ${ }^{1}$ Dipartimento Scientifico e Tecnologico, Università degli Studi di Verona, 37134 Verona, Italy; ${ }^{2}$ Interactions Plantes- \\ Microorganismes et Santé Végétale, UMR INRA 1064/Université de Nice-Sophia Antipolis/CNRS 6192, 400, route des \\ Chappes, BP 167, 06903 Sophia-Antipolis, France; ${ }^{3}$ Dipartimento di Scienze, Tecnologie e Mercati della Vite e del Vino, \\ Università degli Studi di Verona, Villa Ottolini-Lebrecht, 37029 San Floriano di Valpolicella (VR), Italy
}

Submitted 28 September 2007. Accepted 18 February 2008.

\begin{abstract}
Nitric oxide (NO) is involved in diverse physiological processes in plants, including growth, development, response to pathogens, and interactions with beneficial microorganisms. In this work, a dedicated microarray representing the widest database available of NO-related transcripts in plants has been produced with 999 genes identified by a cDNA amplified fragment length polymorphism analysis as modulated in Medicago truncatula roots treated with two NO donors. The microarray then was used to monitor the expression of NO-responsive genes in M. truncatula during the incompatible interaction with the foliar pathogen $\mathrm{Col}$ letotrichum trifolii race 1 and during the symbiotic interaction with Sinorhizobium meliloti 1021. A wide modulation of NO-related genes has been detected during the hypersensitive reaction or during nodule formation and is discussed with special emphasis on the physiological relevance of these genes in the context of the two biotic interactions. This work clearly shows that NO-responsive genes behave differently depending on the plant organ and on the type of interaction, strengthening the need to consider regulatory networks, including different signaling molecules.
\end{abstract}

Nitric oxide (NO) is a lipophilic, highly reactive gaseous molecule that plays important roles in a wide variety of processes, including disease resistance, growth, and development (Delledonne 2005). Given the diverse nature of NO functions, large-scale gene expression studies are required to understand the signaling networks affected (Grun et al. 2006). Recent investigations have documented the transcriptional changes in Arabidopsis thaliana and tobacco plants occurring after treatment with the NO-releasing compound sodium nitroprusside (SNP) (Parani et al. 2004; Polverari et al. 2003; Zago et al. 2006). These studies have confirmed that NO modulates the

\section{A. Ferrarini and M. De Stefano are joint first authors.}

Corresponding authors: Alain Puppo; E-mail: alain.puppo@unice.fr; Telephone: +33 492 386631; Fax: +33 492 386587; and Massimo Delledonne: E-mail: massimo.delledonne@ univr.it; Telephone: +39 045 8027962; Fax: +390458027929.

Current address of E. Baudouin: Laboratoire de Physiologie Cellulaire et Moléculaire des Plantes, Université Pierre et Marie Curie-Paris 6, UMR 7180 UPMC/CNRS, Le Galilée 3, rue Galilée 94200 Ivry sur Seine, France.

* The $e$-Xtra logo stands for "electronic extra" and indicates that one supplemental figure and four supplemental tables are published online. expression of a substantial number of genes that sustain a diversity of cellular functions, in accordance with the pleiotropic role of this molecule in plant physiology. In these analyses, NO was found to modulate the transcription of genes related to signal transduction, such as transcription factors (WRKYs and zinc finger proteins), receptor-like protein kinases, and mitogenactivated protein kinases, genes related to the plant defense response and to protection against oxidative stress such as glutathione- $S$-transferase, glutaredoxin, and catalase (Parani et al. 2004; Polverari et al. 2003; Zago et al. 2006). It also has been reported recently that a strong overlap exists between genes modulated by either $\mathrm{H}_{2} \mathrm{O}_{2}$ or $\mathrm{NO}$ (Zago et al. 2006), supporting the view that NO-dependent gene expression may be regulated by the interplay with other signaling molecules (Neill et al. 2002).

NO accumulates during the plant resistance response to pathogens where it triggers resistance-associated cell death and contributes to the local and systemic induction of defense genes (Delledonne et al. 1998). The recent observation that $\mathrm{NO}$ also is produced in nitrogen-fixing nodules suggests that it also may function in symbiotic interactions (Baudouin et al. 2006). In contrast to pathogenesis, in which plants restrict spreading of the invading pathogen by activation of defense responses, symbiosis with nitrogen-fixing bacteria is characterized by a close association of leguminous plants with bacteria that belong to the Rhizobiaceae family, leading to the formation of new organs, the so-called nodules. Along these lines, it is of interest to analyze the expression profile of a large set of NO-responsive genes during disease resistance and symbiosis. For the present study, we chose the model legume Medicago truncatula cv. Jemalong, which is able to establish both plantsymbiont and plant-pathogen interactions (Oldroyd et al. 2005; Torregrosa et al. 2004). A whole-genome array of this plant is not yet available; therefore, we first performed a cDNA-amplified fragment length polymorphism (AFLP) analysis of $M$. truncatula roots treated with two different NO donors. This open transcript profiling technology allows high-throughput analysis and the detection of rarely expressed transcripts, and has been adopted extensively for large-scale gene expression analyses (Breyne et al. 2003). In a second step, a dedicated cDNA microarray (Medicago truncatula NO-responsive genes array; MtNO) constructed with 999 cDNA fragments whose expression was found to be modulated by NO was used to analyze the expression of $M$. truncatula NO-responsive genes i) upon incompatible interaction with the fungal pathogen Colletotrichum trifolii race 1 and ii) after infection with the nitrogen-fixing soil bacterium Sinorhizobium meliloti 1021. 


\section{RESULTS}

cDNA-AFLP transcript profiling of NO-responsive genes.

Roots from 4-week-old plants grown in an aeroponic chamber were treated with $1 \mathrm{mM}$ SNP or $0.5 \mathrm{mM}$ nitrosoglutathione (GSNO) to assess the effect of different reactive nitrogen molecules $\left(\mathrm{NO}^{+}\right.$released by $\mathrm{SNP}$ and $\mathrm{NO}^{-}$released by GSNO) (Singh et al. 1999; Stamler et al. 1992) on cellular transcriptional responses. Although leaf infiltration of NO donors already was shown to determine a large transcriptional reprogramming (Parani et al. 2004; Polverari et al. 2003; Zago et al. 2006), the effectiveness of SNP treatment on roots was assessed by checking the expression of a gene coding for ferritin by Northern analysis (Supplementary Fig. 1). Ferritin is known to be transcriptionally induced following NO treatment (Murgia et al. 2002). A strong ferritin transcript accumulation was detected $3 \mathrm{~h}$ after dipping in the SNP solution, thus confirming that this treatment is suitable for NO-dependent gene expression analysis. A similar preliminary test was not performed for GSNO because of the lack of any known marker of GSNO transcriptional effect. Then, total RNA from the root tissue was collected at 1 and $3 \mathrm{~h}$ after treatment and subjected to the cDNA-AFLP analysis with an estimated coverage of $55 \%$ of the $M$. truncatula transcriptome (Rombauts et al. 2003). A total of 1,023 cDNA fragments showed altered expression in response to SNP or GSNO compared with control roots dipped in water.

\section{Construction of a MtNO array.}

Bands corresponding to differentially accumulating transcripts were isolated from the gels, reamplified, and cloned. Because the fragments can be contaminated with co-migrating bands, three independent colonies from each of the 1,023 transformation experiments were taken. The entire set of triplicatecloned fragments was then polymerase chain reaction (PCR) amplified, spotted on a microarray, and hybridized with RNA extracted from roots treated with SNP or GSNO and collected $3 \mathrm{~h}$ after the treatment, at which time the highest transcriptional modulation in cDNA-AFLP analysis was observed. By using $\log _{2}$ ratios of $\geq 0.3$ or $\leq-0.3$ (corresponding to fold changes of 1.23 and 0.81 , respectively), approximately $98 \%$ of NO-responsive cDNA fragments showed a detectable modulation in at least one of the three clones, (Supplementary Table 1) which was selected as representative for each of the 999 NO-responsive cDNA fragments. The threshold adopted was selected arbitrarily and settled at relatively low value to include the largest possible number of potentially NO-modulated genes in the array, considering that genes only slightly modulated by NO might be more strongly affected in following biological experiments. In all, 24 cDNA fragments, for which none of the three clones was significantly modulated, were not considered further. The selected 999 fragments were sequenced and compared with the 249,450 M. truncatula expressed sequence tags (EST) available. Only 830 of 999 sequences showed a significant homology with at least one EST present in the database. This data was confirmed by the finding that 832 sequences show homology with sequences from the M. truncatula Gene Index database whereas, for 167 sequences (17\%), no match was found. More detailed functional annotation was provided by mapping genes onto the GeneOntology Consortium structure (Ashburner et al. 2000). Annotation was based on data available at the TIGR M. Truncatula Gene Index (version 8.0) and was complemented by data available on Gene Ontology Annotation Database. Using this annotation, 626 sequences are assigned to 1,539 biological process ontology terms (Fig. 1A), 480 sequences are assigned to 901 molecular function ontology terms (Fig. 1B), and 481 sequences are assigned to 868 cellular component ontology terms (Fig. 1C). In total, 672 sequences had at least one term associated with at least one of the ontologies. (Supplementary Table 2).

A dedicated microarray, designed as an MtNO array, carrying the 999 NO-responsive genes plus 20 control DNA fragments then was prepared. The control DNA genes encoded different nodulins (Rip1, MtN6, MtN9, Enod40, Leg1, Enod12, Enod16, Enod11, Enod20, and MtAnn1), disease marker genes $(P A L$ and $P R-1)$, controls for normalizing gene expression (EFI $\alpha$ and G3PDH), non-Medicago genes (Nebulin, Desmin, and $\mathrm{pSK}$ ) and three ArrayControl Spots (Ambion) as spiking control or as controls for level of nonspecific hybridization.

\section{Expression of genes on the MtNO array after treatment with NO donors in roots and leaves.}

The MtNO array first was used to investigate whether the two different donors modulated the same set of genes and whether cellular responses to SNP and GSNO differed among roots and leaves. Therefore, the microarray was hybridized with RNA extracted from leaves or roots treated with $1.0 \mathrm{mM}$ SNP or $0.5 \mathrm{mM}$ GSNO for $3 \mathrm{~h}$ (two biological replicates), and expression data were analyzed with the statistical analysis of microarrays (SAM) procedure, which allows estimation of the false discovery rate $(\mathrm{FDR} \leq 0.5 \%)$ in combination with a fold change of $\geq 2$ and $\leq 0.5$ (Lohar et al. 2006; Tusher et al. 2001). This fold change was chosen to investigate in a more accurate way NO-related transcriptional changes. According to these criteria, 497 of the 999 genes present on the array still showed a significant change in expression in at least one organ with at least one donor. Despite the high reproducibility observed among the technical and biological replicates, comparison of gene expression between different NO donors and different tissues revealed significant differences (Fig. 2). GSNO and SNP exerted the same modulatory effect on only approximately $11 \%$ of genes in leaves and $1.6 \%$ in roots, and similar expression between leaves and roots was observed for only $1.6 \%$ of the genes responsive to GSNO and for none of the genes responsive to SNP. Thus, modulation of gene expression appears to be strictly dependent on the form of NO and on the cellular response in different tissues. This underlines the observation that the response to NO may vary between different biological phenomena in which NO is produced.

\section{Expression of genes on the MtNO array during pathogenic and symbiotic interactions.}

Resistance of $M$. truncatula to $C$. trifolii race 1 is associated with a localized hypersensitive reaction (HR) and the induction of a large number of defense genes (Torregrosa et al. 2004). By using the cell-permeable NO-specific probe 4,5-diaminofluorescein diacetate (DAF-2DA), which is converted to its fluorescent triazole derivative DAF-2T upon reaction with $\mathrm{NO}$ (Nakatsubo et al. 1998), accumulation of NO was observed at 24 and $48 \mathrm{~h}$ postinoculation (hpi) (Fig. $3 \mathrm{~B}$ and $\mathrm{C}$ ), corresponding to the beginning of fungal penetration in plant tissues (Torregrosa et al. 2004). Mock-inoculated control leaves showed no fluorescence (Fig. 3A). Therefore, total RNA extracted from M. truncatula leaves 24 and $48 \mathrm{hpi}$ with $C$. trifolii race 1 and from mocktreated leaves was used for MtNO microarray hybridizations. The analysis was performed on two biological replicates. Genes with a statistically significant modulation of expression in at least one time point of infection were selected based on a fold change $\geq 2$ and $\leq 0.5$. A change in expression was detected in 275 genes (221 induced and 54 repressed) during the plant response to infection (Fig. 4; Supplementary Table 3). The frequency of biological process ontology terms associated with NO-related genes modulated during HR is reported in Figure 5A.

NO also accumulates in functioning nodules, raising the hypothesis that it may exert functions during symbiotic interac- 
tions unrelated to disease resistance and cell-death activation (Baudouin et al. 2006). To monitor the transcriptional changes of potentially NO-modulated genes in M. truncatula during the symbiotic process, RNA was collected from young (10 days postinoculation [dpi]) and older (20 dpi) nodules for which NO production has been demonstrated previously (Baudouin et al. 2006) as well as from nodulated control roots (two biological replicates). Genes with a statistically significant variation and a fold change $\geq 2$ and $\leq 0.5$ in at least one time point then were classified as upregulated or downregulated following the most prominent modulation. Using these criteria, an expression change was detected for 290 genes (278 induced and 12 repressed) during nodule development (Fig. 4; Supplementary Table 4). The frequency of biological process ontology terms associated with NO-related genes modulated during nodulation is reported in Figure 5B.

To validate the microarray results, we selected 11 genes that were significantly modulated during HR (48 h) or during nodu- lation (10 dpi) or that were modulated in both cases, for evaluation of transcript abundance by real-time reverse-transcriptase (RT)-PCR. The two time points selected showed the higher transcriptional modulation in the two phenomena analyzed. Three biological replicates were used. Results are shown in Table 1. A confirmation of the expression changes detected by microarrays was obtained for seven genes. Discrepancies between the results of these two different techniques are reported in literature with values ranging from 55 to 20 to $30 \%$ (Czechowski et al. 2004; Salzman et al. 2005; Svensson et al. 2006). In this context, our results show a good correlation between microarray and real-time RT-PCR analyses and indicate that our microarray data are reliable.

\section{DISCUSSION}

In this study, we report the isolation and expression analysis of 999 NO-responsive M. truncatula genes. Despite extensive

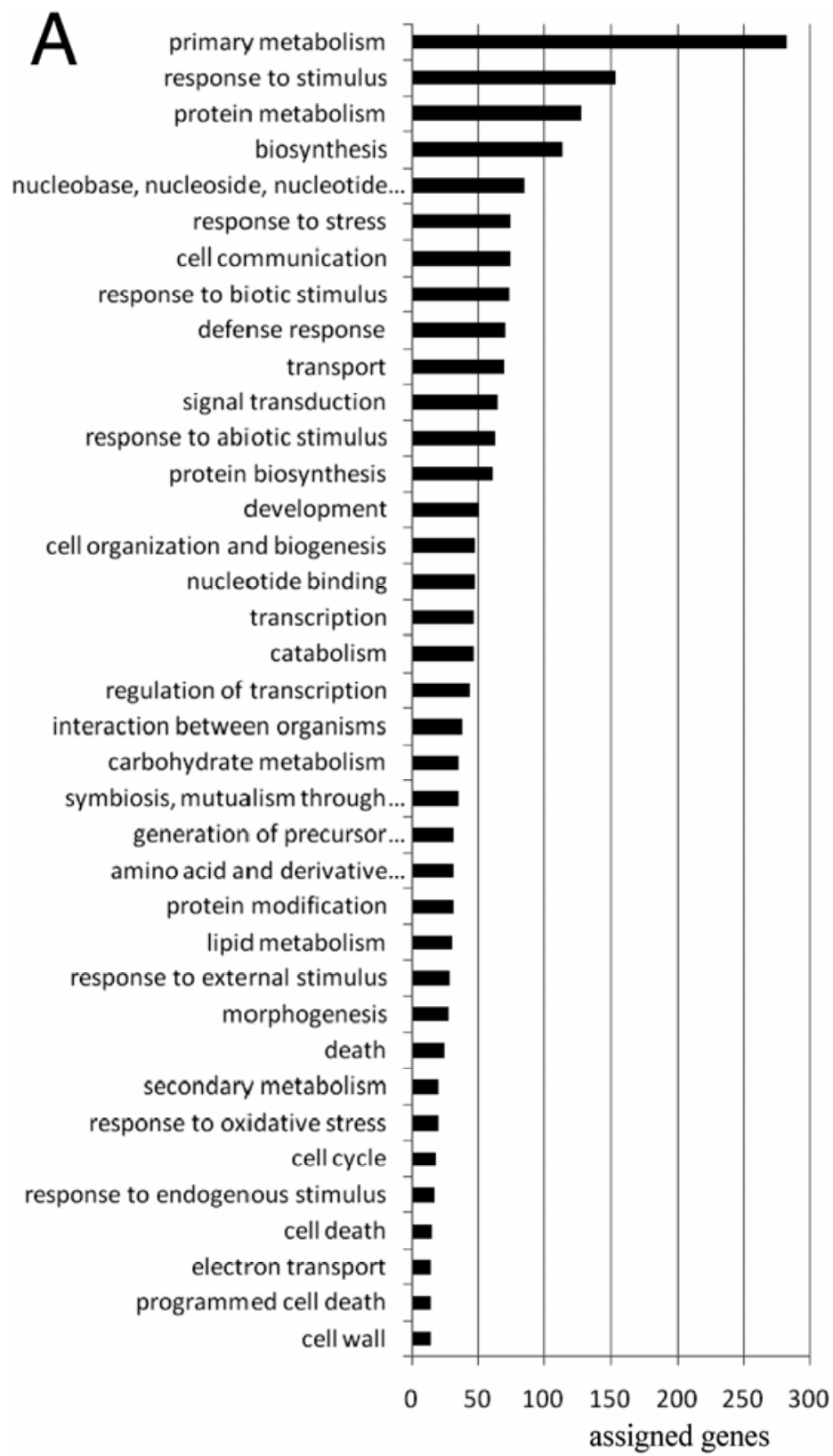

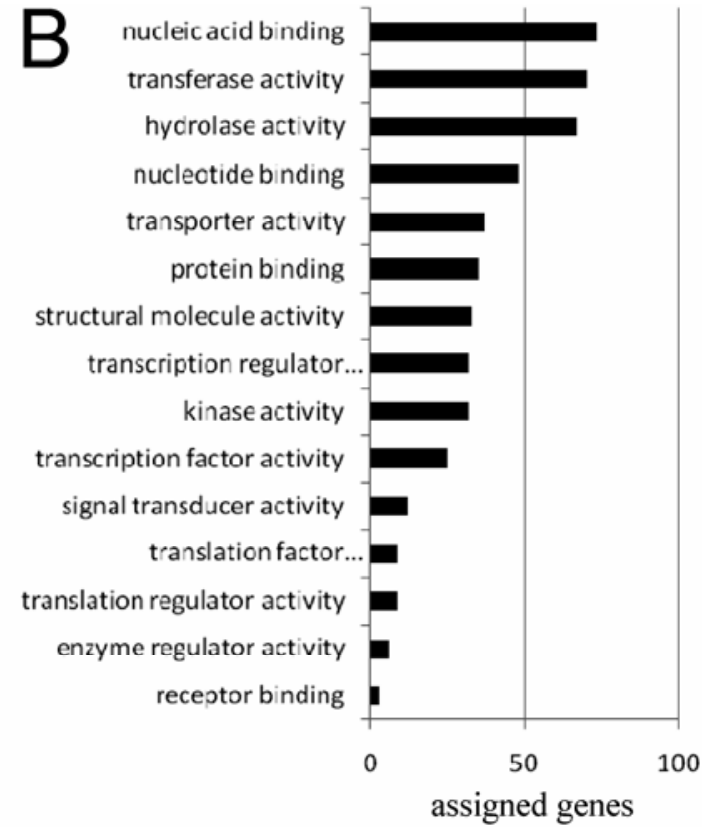

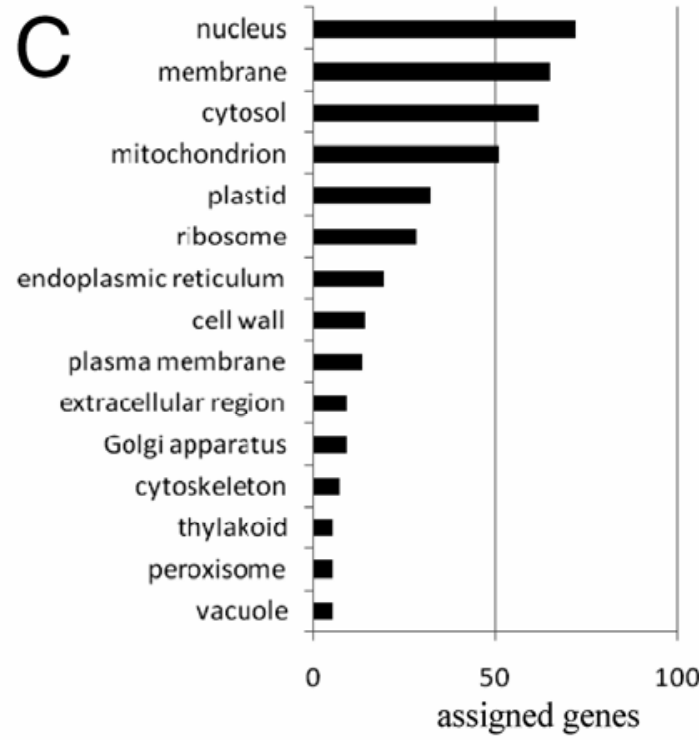

Fig. 1. Distribution of genes in MtNO array with putative functions assigned through annotation using gene ontology. A, Biological process, B, molecular function, and $\mathbf{C}$, cellular component. Assignments are based on the data available at the TIGR Medicago truncatula Gene Index (version 8.0, 19 January 2005) and on data from the Gene Ontology Annotation Database. 
research on NO activity in plant and animal systems, knowledge about the transcriptional effect of NO is still very scarce. This question has been addressed previously in the model species A. thaliana, leading to only partial results (Parani et al.

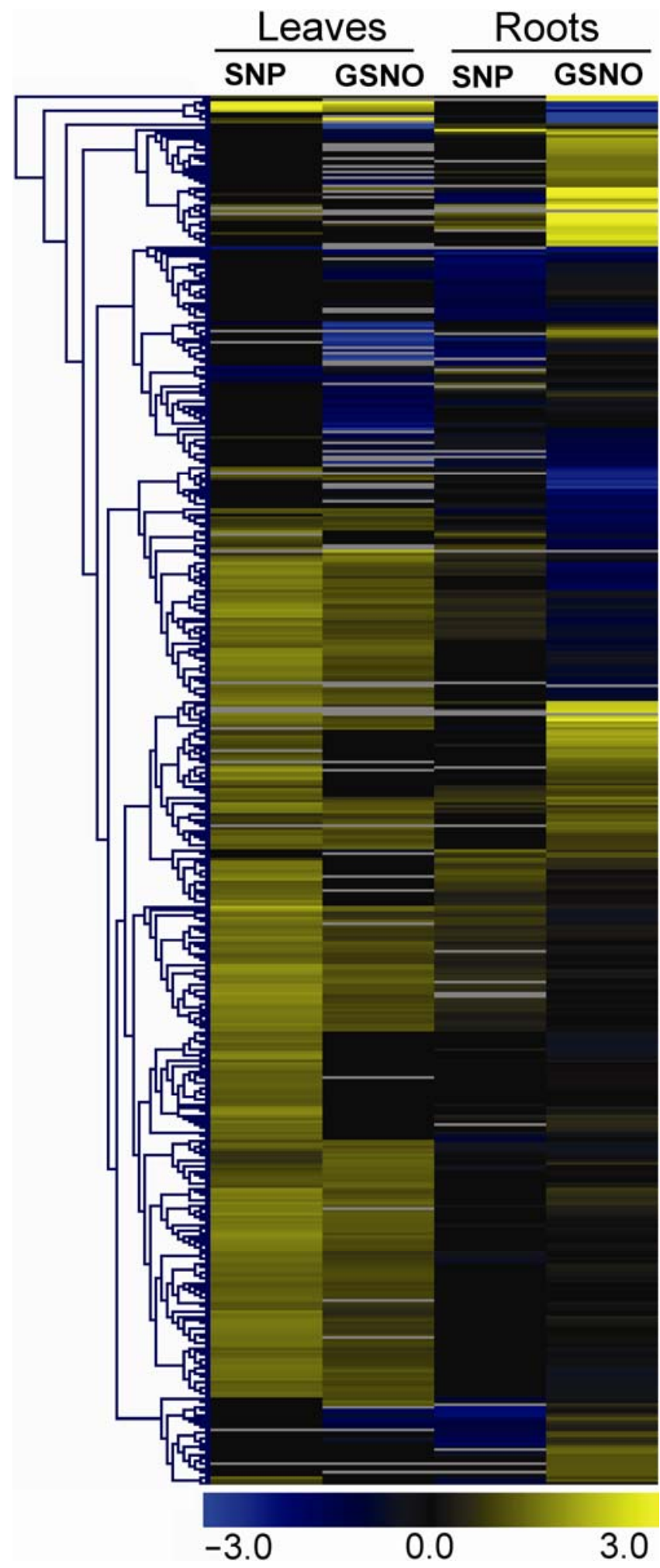

Fig. 2. Gene expression changes during nitric oxide treatments in roots and leaves. Genes are clustered according to expression patterns. Clustering was performed using Euclidean distances and average linkage method. Leaves were infiltrated using a syringe without needle with $1.0 \mathrm{mM}$ sodium nitroprusside (SNP) or $0.5 \mathrm{mM}$ nitrosoglutathione (GSNO) and collected after $3 \mathrm{~h}$; roots were treated by dipping with $1.0 \mathrm{mM}$ SNP or 0.5 mM GSNO for $3 \mathrm{~h}$.
2004; Polverari et al. 2003; Zago et al. 2006). Thus, this work represents, at present, the widest attempt to investigate NO effect on gene expression. M. truncatula has been chosen as a model system because it is a crop plant and allows investigations of different plant-microbe interactions, both pathogenic and symbiotic, in which NO involvement might be of relevance. The $M$. truncatula genome is not fully sequenced and high-output microarray chips were not available at the onset of our work; therefore, we developed a large-scale cDNA-AFLP analysis from roots treated with two NO donors, SNP and GSNO, that enabled us to identify 1,023 putative NO-responsive genes. Of these, 999 genes were validated by microarray analysis and used, together with a set of specific markers for symbiosis and pathogenesis, to build a dedicated MtNO array.

The selected 999 cDNA fragments were sequenced and compared with the M. truncatula Gene Index database, which collects EST from all published EST projects plus transcript sequences from GenBank (Quackenbush et al. 2000), retrieving no match for 167 fragments (17\%) which, therefore, may represent novel $M$. truncatula genes. The analysis of the predicted functions of the 999 genes suggests that NO may control a large range of cellular functions in M. truncatula, including primary metabolism, cell response to environmental cues, and associated regulatory signaling events.

The comparison of gene responsiveness to the two NO donors in roots and in leaves pointed out a low correlation of responses between the two organs on the one hand and between different NO sources applied to the same organ on the other. These results are in good agreement with a previous study of plant response to reactive oxygen species (Gadjev et al. 2006), and may explain the low redundancy observed in previous analyses of gene expression in response to NO donors (Huang et al. 2002; Parani et al. 2004; Polverari et al. 2003). Moreover, they illustrate that data obtained using NO donors should be taken with extreme care and must be interpreted in the correct physiological context. Therefore, we analyzed the expression of genes in the MtNO array during pathogenic and symbiotic interactions.

\section{Expression of NO-responsive genes following $C$. trifolii infection.}

M. truncatula develops resistance upon infection with $C$. trifolii race 1 (Torregrosa et al. 2004). In this work, we report that this resistance is accompanied by a transient production of NO and show how NO-responsive genes are expressed during this specific interaction. Of the 999 NO-related genes examined, 275 presented a significant variation in expression and were mainly upregulated, with the strongest induction at 48 hpi, in agreement with Torregrosa and associates (2004), who detected the widest accumulation of defense-related genes at this time point. Only 41 genes modulated in this model system had been identified already in expression analyses or in EST libraries from the same interaction (Torregrosa et al. 2004), while 234 additional genes have been identified in this work. The disease resistance pathway induced by $C$. trifolii in $M$. truncatula shows some similarities at the transcriptional level to other best-characterized pathosystems. Genes with similarity to genes essential for the development of resistance in Arabidopsis and other species such as NIM-1 (TC103386), EDS-1like protein (TC101591) (Despres et al. 2000; Liu et al. 2002), the Arabidopsis Disease Resistance Protein AIG-1 (TC95233) (Reuber and Ausubel 1996), and Hsr201 (TC93957), considered a marker of an HR (Czernic et al. 1996; Takahashi et al. 2004), have been identified in this work as NO responsive and transcriptionally activated upon hypersensitivity in alfalfa.

In addition, NO-related genes involved in reactive oxygen species generation or in plant tolerance to oxidative stresses, such as a gene showing partial similarity to a class III peroxi- 
dase precursor (TC105151) and a thioredoxin h (TC100552), both shown to be $\mathrm{NO}$ or $\mathrm{H}_{2} \mathrm{O}_{2}$ inducible in other systems (Zago et al. 2006), a serine hydroxymethyltransferase (TC106714), and a spermidine synthase 1 (TC101378), were found to be induced during the interaction with $C$. trifolii, in agreement with the detection of an oxidative burst associated with the resistance of $M$. truncatula to $C$. trifolii (Torregrosa et al. 2004). Recent evidences indicate that class III peroxidase plays a significant role in generating $\mathrm{H}_{2} \mathrm{O}_{2}$ during the Arabidopsis defense response and in conferring resistance to a wide range of pathogens (Bindschedler et al. 2006).

Phospholipids-derived products play an important role in many cellular processes, including biosynthesis of jasmonic acid and defense signaling (Ryu 2004). Thus, it is not surprising that genes related to the lipid signaling pathway (TC101452, TC100188, and TC108506) are among NO-related transcripts induced during HR: NO is likely to affect lipid peroxidation in a complex way through interaction of its reactive forms with lipid radicals or enzymes involved in lipid peroxidation (Hogg and Kalyanaraman 1999).

Interestingly, two NO-induced genes related to a $26 \mathrm{~S}$ proteasome degradation pathway (TC100785 and TC101418), an ubiquitin-protein ligase 2 (TC99995), and two ubiquitin-activating enzyme-like proteins (SUMO) (TC95241 and TC95701) are induced during HR. Protein modifications and degradation already have been implicated in regulation of defense responses. In fact, evidence has shown the involvement of ubiquitine/26S proteasome in resistance to pathogens (Vierstra 2003); also, sumoylation seems to be an essential protein modification step for several biological processes, including resistance (Novatchkova et al. 2004).

Finally, other NO-responsive genes induced during HR encode components of signal transduction cascades. Among them are kinases, (TC101908, TC107107, and TC100773), phosphatases (TC102800 and TC98241), and transcription factors of the zinc finger (TC100777), bZIP (TC95362), and WRKY (TC108267) families. This last example is especially interesting because members of the WRKY gene family can regulate the expression of resistance in Arabidopsis and other species (Du and Chen 2000; Eulgem and Somssich 2007). Thus, it will be interesting to investigate further the role of WRKYs as possible transcriptional activators of defense genes in M. truncatula.

Although an involvement of NO in mediating the transcriptional response to $C$. trifolii cannot be established yet, the wide correlations found between NO-related and HR-related gene expression is interesting and opens the way for further investigations about NO functions on resistance in M. truncatula.

\section{Expression of NO-responsive genes during symbiosis.}

We and others have recently observed that NO is produced in root nodules formed upon rhizobial infection (Baudouin et al. 2006; Pii et al. 2007). On the basis of these results, we analyzed the expression of NO-responsive genes in young nodules (10 dpi) and in mature ones (20 dpi). Of the 999 genes responding to NO in Medicago roots, 290 also were regulated in nodules, and mainly in young nodules, supporting the hypothesis that NO may participate to nodule development, as suggested by Pii and associates (2007).
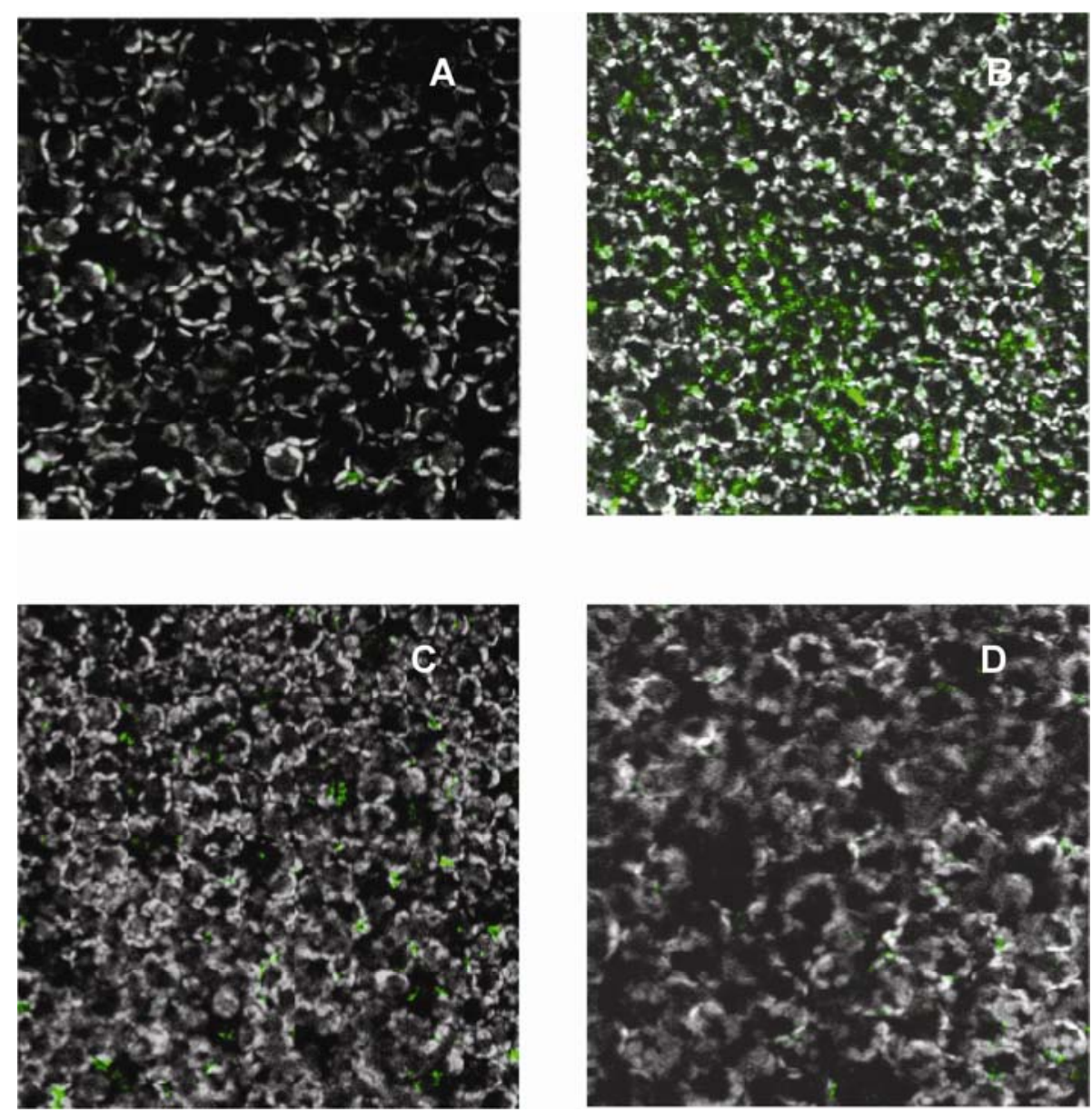

Fig. 3. Visualization of nitric oxide (NO) by fluorescence microscopy using 4,5-diaminofluorescein diacetate in epidermis of Medicago truncatula during the pathogenic infection. Images are representative of confocal laser scanning microscopy detection of NO at different time points after Colletotrichum trifolii race 1 infection. A, Mock treated negative control; B, 24 h postinoculation (hpi); C, 48 hpi; and D, 72 hpi. 
Following plant-rhizobia recognition, the root hairs undergo complex developmental changes to promote nodule formation (Stougaard 2000), such as changes in the profile of flavonoids released in root exudates which can induce bacterial nod gene
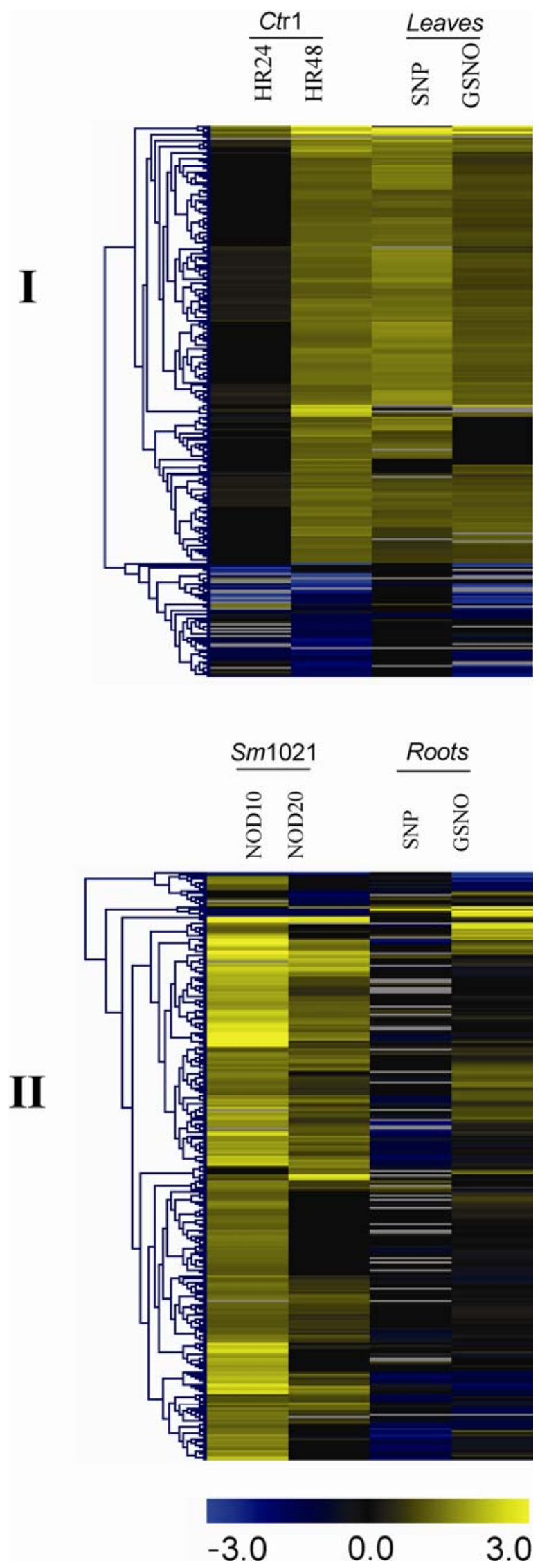

expression (Cooper 2004; Peters and Long 1988). Chalcone synthase (CHS) genes have been reported to be upregulated in $M$. truncatula following inoculation with $S$. meliloti (Lohar et al. 2006), whereas silencing of a CHS gene resulted in inhibition of root nodule formation (Wasson et al. 2006). Interestingly, several genes involved in flavonoid biosynthesis identified as NO-related by our analysis also were upregulated at $10 \mathrm{dpi}$ (TC100398, TC100399, and TC100400).

The modifications of the developmental program of root hairs during nodulation involve the activity of several signal transduction components (Madsen et al. 2003; Radutoiu et al. 2003; Tirichine et al. 2007). Accordingly, genes coding for several kinases (TC101043, TC102457, TC108166, TC94925, and TC109034), receptor-like kinases (TC103880 and TC96145), and transcription factors (TC95828 and TC107215) are upregulated in young nodules. Nodule edification also requires plant cells undergoing endoreduplication cycles that are tightly dependent on specific proteasome-dependent protein degradation (Kondorosi et al. 2005). Two genes detected by our analysis as putatively NO-related (TC101765 and TC106801), both operating in the proteasome-dependent protein degradation pathway, and several other genes involved in proteolysis (TC94330, TC94369, and TC97079) are activated in nodules.

Redox signaling also plays a key role in the establishment of a functioning nodule (Frendo et al. 2005; Lee et al. 2005; Wisniewski et al. 2000). The enhanced expression in nodules of two genes encoding $\mathrm{H}_{2} \mathrm{O}_{2}$-generating proteins - a peroxidase (TC95986) and a germin-like oxalate oxidase (TC95759) - is worth mentioning and suggests possible cross talks between $\mathrm{NO}$ and $\mathrm{H}_{2} \mathrm{O}_{2}$ signaling, as demonstrated in other systems (Zaninotto et al. 2006). Moreover, a gene encoding a glutathione synthetase (TC108090) involved in the control of cellular redox responses via protein thiol status and a gene involved in glutathione-conjugate transport (TC94904) present similar expression patterns. Glutathione synthetase previously has been shown to be involved in nodule development (Frendo et al. 2005), and recently, we described the regulation of glutathione synthesis by NO in M. truncatula roots (Innocenti et al. 2007).

Reprogramming of plant cell primary metabolism is necessary for the integration of large amounts of ammonium produced by bacteroids into amino acids (Udvardi and Day 1997). Dicarboxylic acids deriving from sucrose breakdown are used by microsymbionts as carbon sources and provide carbon skeletons for the assimilation of the produced ammonia into amino acids (Gordon et al. 1999; Udvardi and Day 1997). Sucrose synthase is the major enzyme responsible for sucrose degradation in mature nodules (Albrecht and Mustroph 2003; Gordon et al. 1999). A functional implication of sucrose synthase in efficient nitrogen fixation was demonstrated recently using antisense transgenic plants (Baier et al. 2007). In this framework, it is interesting to observe that nodulation can affect transcription of genes coding for two sucrose synthases (TC95820 and TC 100410) and a sucrose transporter (TC944389), and of genes involved in glycolysis and dicarboxylic acid biosynthesis, such as glyceraldehyde-3-phosphate dehydrogenase (TC106518), isocytrate dehydrogenase (TC94329), and a cytosolic malate de-

Fig. 4. Gene expression changes during the incompatible Medicago truncatula-Colletotrichum trifolii race 1 (Ctr1) and the symbiotic M. truncatula-Sinorhizobium meliloti (Sm1021) interactions, and in response to nitric oxide donor treatment (sodium nitroprusside [SNP] and nitrosoglutathione [GSNO]) in leaves or roots. Genes are clustered according to expression patterns. Clusters were calculated using Euclidean distances and average linkage method. Cluster I: genes modulated during hypersensitive response. Cluster II: genes modulated during nodule development. 

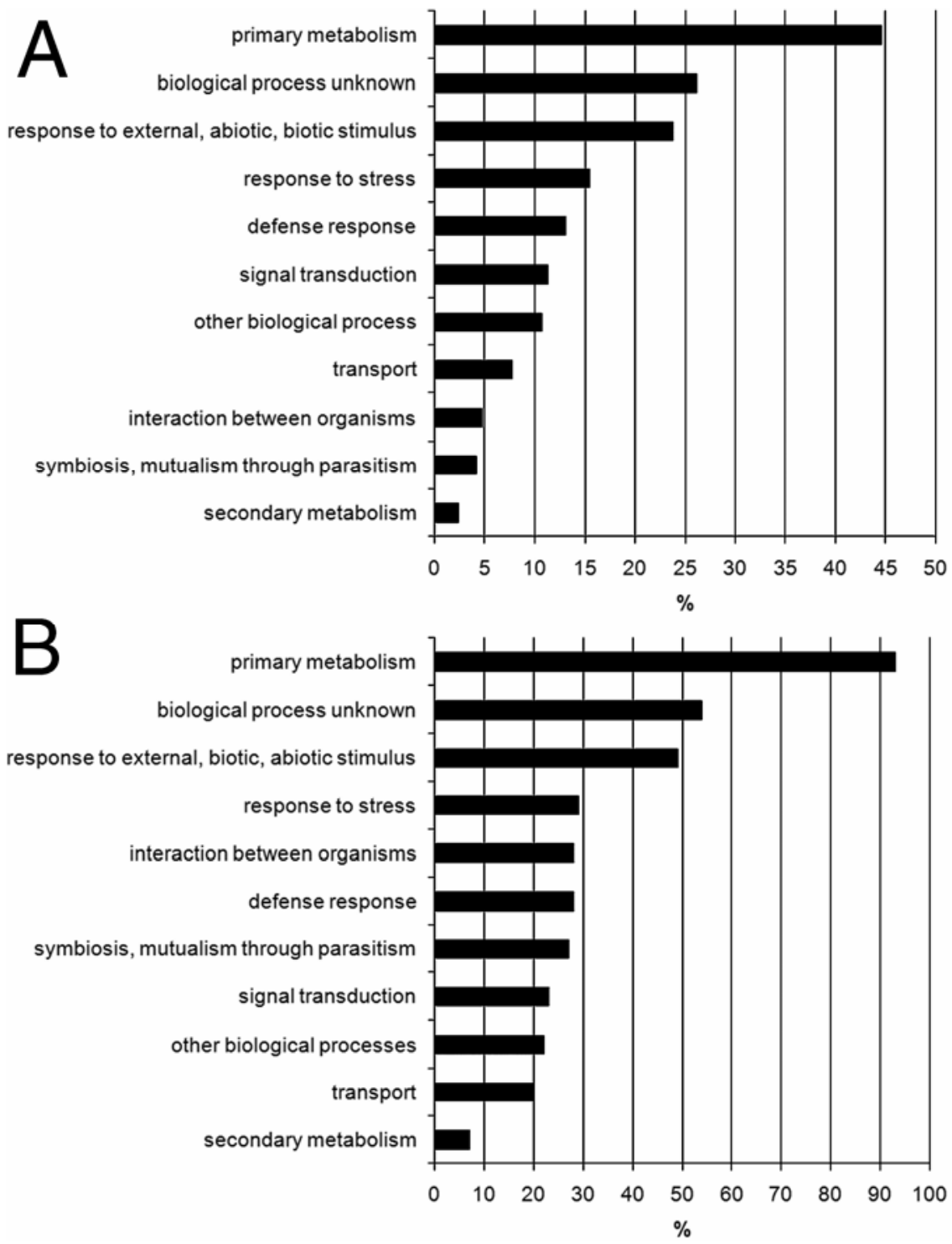

Fig. 5. Frequencies of gene ontology terms associated to genes modulated $\mathbf{A}$, during the hypersensitive reaction to Colletotrichum trifolii race 1 and $\mathbf{B}$, during interaction with Sinorhizobium meliloti. Values are expressed as percentage of genes assigned to a particular term over the number of genes with a biological process term associated. Assignments are based on the data available at the TIGR Medicago truncatula Gene Index (version 8.0, 19 January 2005) and on data from the Gene Ontology Annotation Database.

Table 1. Validation of expression patterns by real-time reverse-transcriptase polymerase chain reaction (RT-PCR) ${ }^{\mathrm{a}}$

\begin{tabular}{|c|c|c|c|c|c|c|c|}
\hline \multirow[b]{2}{*}{ Gene ID } & \multirow[b]{2}{*}{ Definition } & \multicolumn{2}{|c|}{ Microarray } & \multicolumn{4}{|c|}{ Real-time RT-PCR } \\
\hline & & HR48 & NOD10 & HR48 & $P$ value & NOD10 & $P$ value \\
\hline \multicolumn{8}{|c|}{ Modulated specifically during $\mathrm{HR}^{\mathrm{b}}$} \\
\hline TC98241 & Putative phosphatase & 2.46 & $\ldots$ & 1.30 & 0.028 & $\ldots$ & $\ldots$ \\
\hline TC108506 & Fatty acid hydroxilase & 2.50 & $\ldots$ & 2.62 & $\mathbf{0 . 0 3 0}$ & $\ldots$ & $\ldots$ \\
\hline TC100886 & Vestitore reductase & 2.46 & $\ldots$ & 0.45 & 0.030 & $\ldots$ & $\ldots$ \\
\hline \multicolumn{8}{|c|}{ Modulated specifically during nodulation } \\
\hline TC100410 & Sucrose synthase & $\ldots$ & 14.82 & $\ldots$ & $\ldots$ & 5.58 & 0.07 \\
\hline TC101043 & Phosphofructokinase & $\ldots$ & 4.76 & $\ldots$ & $\ldots$ & 9.32 & 0.02 \\
\hline ТC96961 & Syntaxin & $\ldots$ & 2.55 & $\ldots$ & $\ldots$ & 0.74 & 0.31 \\
\hline TC106808 & Glutamine synthetase & $\ldots$ & 4.26 & $\ldots$ & $\ldots$ & 1.16 & 0.34 \\
\hline TC100430 & Cytosolic malic dehydrogenase & $\ldots$ & 3.66 & & $\ldots$ & 12.64 & 0.1 \\
\hline \multicolumn{8}{|c|}{ Modulated specifically during both HR and nodulation } \\
\hline TC101701 & Acyl-CoA oxidase & 2.41 & 2.85 & 0.55 & 0.017 & 109.14 & 0.001 \\
\hline ТC94441 & Glutaredoxin & 0.058 & 2.55 & 0.81 & 0.073 & 18.38 & 0.014 \\
\hline TC100188 & Lipoxygenase & 2.27 & 2.10 & 1.30 & 0.1 & 14.32 & 0.0001 \\
\hline
\end{tabular}

a The expression of 11 modulated genes belonging to different functional categories and expression clusters was verified by real-time RT-PCR. The experiment was performed on three biological replicates. Expression values are expressed as ratios between analyzed samples and controls. $P$ values supporting the significance of real-time data also are provided. Validated data are shown in bold.

${ }^{\mathrm{b}} \mathrm{HR}=$ hypersensitive response. 
hydrogenase (TC100430). Concomitantly, a modified protein metabolism is reflected by the upregulation of 15 genes corresponding to different ribosomal proteins and by increased transcription of genes encoding important enzymes, such as glutamine (TC106808, TC106913, and TC106729) and asparagine synthases (TC100393) and an amino acid transporter (TC97228).

Altogether, these data point toward new directions for further understanding of the molecular events underlying nodule formation and the possible contributions of NO to nodule metabolism.

\section{NO-responsive genes during pathogenic}

and symbiotic interactions: commonalities and differences.

The comparison between transcriptional changes detected on the MtNO array in the incompatible interaction or in the symbiotic interaction showed limited correlations, either direct or inverse. Only 10 NO-related genes were significantly upregulated in both model systems and 47 genes showed an opposite modulation in pathogenic versus symbiotic conditions. Although this is not surprising, given the diverse nature of the two plant-microbe interactions, these genes might be of special interest because they might reflect crucial control points in which compatible interactions diverge from incompatible ones. Among the 10 genes significantly upregulated in both model systems are genes related to lipid metabolism (TC101701 and TC100188), in agreement with the importance of lipid synthesis during development processes and stress responses, and genes involved in signal transduction (TC100784, shaggyrelated protein kinase) or in the breakdown of alcohols (alcohol dehydrogenases TC100661 and TC95827).

In all, 47 NO-responsive genes showed an opposite regulation in pathogenesis and symbiosis. Although some differences may be ascribed to organ specificity, most of these differences are not organ dependent (i.e., the genes respond similarly to $\mathrm{NO}$ in both leaves and roots). One such example is the already mentioned sucrose synthase gene TC100410, upregulated in symbiosis and downregulated in HR development, reflecting activation of glycolysis in nodules, and the already reported accumulation of sucrose in incompatible interactions (GomezAriza et al. 2007; Scharte et al. 2005). The differential regulation of glutaredoxin (TC94441) might reflect the need of a reducing environment in nodules (Harrison et al. 2005) and the downregulation of the overall reducing capacity of the plant following pathogen attack (Mou et al. 2003). Signal transduction components also were differentially regulated in the two processes, such as transcription factors (TC95828, TC107215, and TC111312) and protein kinases (TC108166 and TC94925). These findings suggest that several different regulating components, possibly affected by NO production, modulate gene expression in different systems, leading, in some cases, to antagonist effects.

\section{Conclusion.}

This work highlights the effect of NO on plant transcripts in both leaves and roots and, thus, points to a possible role for this molecule as a transcriptional modulator in the different plantmicrobe interactions in which it is produced. It clearly shows that NO-responsive genes behave differently depending on the plant organ and on the type of interaction. This further demonstrates the need for considering regulatory networks, including different signaling molecules, in order to have a holistic view of gene transcription changes during plant-microbe interactions. However, the results presented here suggest that NO might be involved in the transcriptional changes induced by HR during pathogenic interaction and might regulate important processes of symbiotic nodule development and functioning.

\section{MATERIALS AND METHODS}

\section{Plant inoculations and treatments.}

$M$. truncatula cv. Jemalong seed were scarified in $1 \mathrm{M}$ $\mathrm{H}_{2} \mathrm{SO}_{4}(8 \mathrm{~min}$ ), sterilized in $6 \%$ bleach solution (4 min), and then rinsed with sterile distilled water. Sterilized seedlings germinated for $48 \mathrm{~h}$ on $0.5 \%$ agarose were planted in sand watered with modified Farhaeus medium (Boisson-Dernier et al. 2001). For treatments with NO donors, plants were grown in an aeroponic growth chamber with nutritive medium, with a day and night temperature of $22^{\circ} \mathrm{C}$ and a photoperiod of $16 \mathrm{~h}$. After 4 weeks, plants were transferred in modified Farhaeus liquid medium only (control) or containing $1 \mathrm{mM} \mathrm{SNP}$ or 0.5 $\mathrm{mM}$ GSNO for 1 or $3 \mathrm{~h}$, as indicated. For infection with $C$. trifolii race 1, seedlings were transferred in soil and detached leaves taken from 4-week-old plants were used for analysis. Fungal growth and inoculation procedures were performed as described (Torregrosa et al. 2004). Inoculated and control leaves were collected 24, 48, and 72 hpi. For S. meliloti 1021 inoculation, seedlings were transferred to sterile sand and watered with nutritive solution in the absence of nitrogen supply. Plants were inoculated when 7 days old. Roots and nodules were collected 10 and $20 \mathrm{dpi}$. The production of NO was visualized using DAF-2 DA as described (Foissner et al. 2000). Total RNA was isolated from roots and leaves using Trizol reagent (Invitrogen, Paisley, U.K.).

\section{Northern blot.}

RNA was extracted using Trizol for both leaves and cells (Invitrogen). RNA at $5 \mu \mathrm{g}$ per sample was used in RNA gel electrophoresis. RNA then was blotted overnight onto a nylon membrane Hybond-N+ (Amersham Biosciences, Piscataway, NJ, U.S.A.), crosslinked to the membrane with $2 \mathrm{~h}$ baking at $80^{\circ} \mathrm{C}$ and hybridized with a radioactive probe using the RediprimeII Amersham kit (Amersham Biosciences). The Arabidopsis ferritin probe was a Not1-EcoR1 fragment (approximately $600 \mathrm{bp}$ ) from the Atfer1 cDNA subcloned in pBluescript (Gaymard et al. 1996).

\section{cDNA-AFLP analysis.}

Poly $(\mathrm{A})^{+}$RNA was isolated from total RNA samples using biotinylated oligo-dT (Promega Corp., Madison, WI, U.S.A.) in combination with streptavidin magnetic beads (Dynabeads M-280 Streptavidin; Oxoid, Basingstoke, U.K.) and then was used for cDNA synthesis. The cDNA-AFLP technique was performed as described (Breyne et al. 2002) using 32 primer combinations. The ${ }^{33} \mathrm{P}$-labeled cDNA fragments were separated on $6 \%$ polyacrylamide gels and visualized by autoradiography. Bands showing a marked variation in intensity in SNP- or GSNO-treated samples compared with the controls were cut out from the gel, reamplified, and cloned.

\section{Construction of dedicated microarrays.}

Clones were kept as bacteria stocks at $-80^{\circ} \mathrm{C}$. Each clone was PCR amplified. PCR products were cleaned with Millipore (Billerica, MA, U.S.A.) filter plates and eluted in $3 \times \mathrm{SSC}$ $(1 \times \mathrm{SSC}$ is $0.15 \mathrm{M} \mathrm{NaCl}$ plus $0.015 \mathrm{M}$ sodium citrate) to reach a final concentration of 50 to $300 \mathrm{ng} / \mu \mathrm{l}$. DNA was spotted onto aminosilane-coated slides with a SpotArray24 microarray spotter (Perkin-Elmer Life Sciences, Zaventem, Belgium). DNA was UV cross-linked onto the slide. Slides were stored in the dark at room temperature.

\section{RNA labeling and microarray hybridization.}

mRNA was labeled with either Alexa-555 (references) or Alexa-647 (samples) dies (Invitrogen) using SuperScript Indirect cDNA Labeling System (Invitrogen), according to the 
manufacturer's instructions. Samples and reference probes were mixed, vacuum dried, and resuspended in Microarray hybridization solution (Amersham Biosciences). Hybridization was performed for at least 16 to $18 \mathrm{~h}$ at $42^{\circ} \mathrm{C}$.

\section{Image acquisition and data normalization.}

The hybridization signal was detected with a ScanArray 4000XL (PerkinElmer Life Sciences) and quantified with ScanArray Express 3.0 software (PerkinElmer Life Sciences). The output files were normalized with LIMMA array analysis software (Smyth et al. 2005) using the functions background correction and Lowess correction. The ratios between the Alexa 647 and Alexa 555 signals were $\log _{2}$ transformed for further data analysis.

\section{Statistical analysis.}

Differential gene expression was assessed using the SAM analysis (Tusher et al. 2001). Data were considered as significant with an FDR $<0.05 \%$ and a fold change ratio between 0.5 and 2. A hierarchical clustering procedure was used to test for coexpression using simple Euclidean distances.

\section{Real-time PCR analysis.}

Total RNA samples were extracted using Trizol reagent (Invitrogen). A set of primers specific for 11 genes analyzed was designed as follows: AcylCoa forward (for) (TC101701), AAGCTGCTCTGAAGCTTGTC; AcylCoa reverse (rev) (TC101701), CTGACAGTTTGTGGATTGCC; Synt for (TC96961), GTCAACACTTCGCTTCTTCG; Synt rev, AATC ATCCACCCAAGATGGC; PPK for (TC101043), AAGACCC TGCCCATTACTCT; PPK rev, GTAACCTGCCATTGCTC CAT; MDH for (TC100430), TCCCAAGCTTCTGCTCT TGA; MDH rev, CTCAGGAATGGATGGAGCAA; GS for (TC106808), TGAGGAGCAAAGCAAGGACT; GS rev, ATC TTCTCCAGGAGCTTGAC; Phos for (TC101043), TTTGAA GCTTGAGGGAGGTG; Phos rev, CCTCTCCATTGCTCCA ATCA; Lipoxy for (TC100188), AAGGATTGACTTCCAGA GGC; Lipoxy rev, AGGTGAGGGAATTGGATTCC; Vest for (TC100886), AAGGCTGTGTCGGGATATTC; Vest rev, AAA ATGCCTAATGCGCCGTC; Fat for (TC108506), CCTTCAA CTACTCCTGCGTT; Fat rev, GGATGTTCAGTCTTTGG CTG; Susy for (TC100410), CTTGAAGCAAAGGGAAA GGG; Susy rev, CACCAAATGCACCATCAGTC; Glutared for (TC94441), AGCCGTTGAACTCGATTCTG; and Glutared rev, CAATGTGGTTGCCGCCAATA). Actin 11 (TC106785) was used as internal normalizer (Actin11 for, GCTATTCAGG CCGTTCTTTC and Actin11 rev, AAGGGCATAACCCTCG TAGA). Thermal cycle conditions used were $95^{\circ} \mathrm{C}$ for $40 \mathrm{~s}$, $55^{\circ} \mathrm{C}$ for $30 \mathrm{~s}$, and $72^{\circ} \mathrm{C}$ for $50 \mathrm{~s}$, all repeated for 40 cycles.

\section{LITERATURE CITED}

Albrecht, G., and Mustroph, A. 2003. Localization of sucrose synthase in wheat roots: Increased in situ activity of sucrose synthase correlates with cell wall thickening by cellulose deposition under hypoxia. Planta 217:252-260

Ashburner, M., Ball, C. A., Blake, J. A., Botstein, D., Butler, H., Cherry, J. M., Davis, A. P., Dolinski, K., Dwight, S. S., Eppig, J. T., Harris, M. A., Hill, D. P., Issel-Tarver, L., Kasarskis, A., Lewis, S., Matese, J. C., Richardson, J. E., Ringwald, M., Rubin, G. M., and Sherlock, G. 2000. Gene ontology: Tool for the unification of biology. Nat. Genet. 25:25-29.

Baier, M. C., Barsch, A., Kuster, H., and Hohnjec, N. 2007. Antisense repression of the Medicago truncatula nodule-enhanced sucrose synthase leads to a handicapped nitrogen fixation mirrored by specific alterations in the symbiotic transcriptome and metabolome. Plant Physiol. 145:1600-1618.

Baudouin, E., Pieuchot, L., Engler, G., Pauly, N., and Puppo, A. 2006. Nitric oxide is formed in Medicago truncatula-Sinorhizobium meliloti functional nodules. Mol. Plant-Microbe Interact. 19:970-975.

Bindschedler, L. V., Dewdney, J., Blee, K. A., Stone, J. M., Asai, T.,
Plotnikov, J., Denoux, C., Hayes, T., Gerrish, C., Davies, D. R., Ausubel, F. M., and Paul Bolwell, G. 2006. Peroxidase-dependent apoplastic oxidative burst in Arabidopsis required for pathogen resistance. Plant J. 47:851-863.

Boisson-Dernier, A., Chabaud, M., Garcia, F., Becard, G., Rosenberg, C., and Barker, D. G. 2001. Agrobacterium rhizogenes-transformed roots of Medicago truncatula for the study of nitrogen-fixing and endomycorrhizal symbiotic associations. Mol. Plant-Microbe Interact. 14:695-700.

Breyne, P., Dreesen, R., Vandepoele, K., De Veylder, L., Van Breusegem, F., Callewaert, L., Rombauts, S., Raes, J., Cannoot, B., Engler, G., Inze, D., and Zabeau, M. 2002. Transcriptome analysis during cell division in plants. Proc. Natl. Acad. Sci. U.S.A. 99:14825-14830.

Breyne, P., Dreesen, R., Cannoot, B., Rombaut, D., Vandepoele, K., Rombauts, S., Vanderhaeghen, R., Inze, D., and Zabeau, M. 2003. Quantitative cDNA-AFLP analysis for genome-wide expression studies. Mol. Genet. Genomics 269:173-179.

Cooper, J. 2004. Multiple responses of rhizobia to flavonoids during legume root infection. Adv. Bot. Res. 41:1-62.

Czechowski, T., Bari, R. P., Stitt, M., Scheible, W.-R., and Udvardi, M. K. 2004. Real-time RT-PCR profiling of over 1400 Arabidopsis transcription factors: Unprecedented sensitivity reveals novel root- and shootspecific genes. Plant J. 38:366-379.

Czernic, P., Hsiou, C. H., and Yves, M. 1996. Characterization of hsr201 and hsr515, two tobacco genes preferentially expressed during the hypersensitive reaction provoked by phytopathogenic bacteria. Plant Mol. Biol. 31:255-265.

Delledonne, M. 2005. NO news is good news for plants. Curr. Opin. Plant Biol. 8:390-396.

Delledonne, M., Xia, Y., Dixon, R. A., and Lamb, C. 1998. Nitric oxide functions as a signal in plant disease resistance. Nature 394:585-588

Despres, C., DeLong, C., Glaze, S., Liu, E., and Fobert, P. R. 2000. The Arabidopsis NPR1/NIM1 protein enhances the DNA binding activity of a subgroup of the TGA family of bZIP transcription factors. Plant Cell 12:279-290.

Du, L., and Chen, Z. 2000. Identification of genes encoding receptor-like protein kinases as possible targets of pathogen- and salicylic acid-induced WRKY DNA-binding proteins in Arabidopsis. Plant J. 24:837-847.

Eulgem, T., and Somssich, I. E. 2007. Networks of WRKY transcription factors in defense signaling. Curr. Opin. Plant Biol. 10:366-371.

Foissner, I., Wendehenne, D., Langebartels, C., and Durner, J. 2000. In vivo imaging of an elicitor-induced nitric oxide burst in tobacco. Plant J. 23:817-824.

Frendo, P., Harrison, J., Norman, C., Hernandez Jimenez, M. J., Van de Sype, G., Gilabert, A., and Puppo, A. 2005. Glutathione and homoglutathione play a critical role in the nodulation process of Medicago truncatula. Mol. Plant-Microbe Interact. 18:254-259.

Gadjev, I., Vanderauwera, S., Gechev, T. S., Laloi, C., Minkov, I. N., Shulaev, V., Apel, K., Inze, D., Mittler, R., and Van Breusegem, F. 2006. Transcriptomic footprints disclose specificity of reactive oxygen species signaling in Arabidopsis. Plant Physiol. 141:436-445.

Gaymard, F., Boucherez, J., and Briat, J. F. 1996. Characterization of a ferritin mRNA from Arabidopsis thaliana accumulated in response to iron through an oxidative pathway independent of abscisic acid. Biochem. J. 318:67-73.

Gomez-Ariza, J., Campo, S., Rufat, M., Estopa, M., Messeguer, J., Segundo, B. S., and Coca, M. 2007. Sucrose-mediated priming of plant defense responses and broad-spectrum disease resistance by overexpression of the maize pathogenesis-related PRms protein in rice plants. Mol. PlantMicrobe Interact. 20:832-842.

Gordon, A. J., Minchin, F. R., James, C. L., and Komina, O. 1999. Sucrose synthase in legume nodules is essential for nitrogen fixation. Plant Physiol. 120:867-878.

Grun, S., Lindermayr, C., Sell, S., and Durner, J. 2006. Nitric oxide and gene regulation in plants. J. Exp. Bot. 57:507-516.

Harrison, J., Jamet, A., Muglia, C.I., Van de Sype, G., Aguilar, O. M., Puppo, A., and Frendo, P. 2005. Glutathione plays a fundamental role in growth and symbiotic capacity of Sinorhizobium meliloti. J. Bacteriol. 187:168-174.

Hogg, N., and Kalyanaraman, B. 1999. Nitric oxide and lipid peroxidation. Biochim. Biophys. Acta Bioenerg. 1411:378-384

Huang, X., Kiefer, E., von Rad, U., Ernst, D., Foissner, I., and Durner, J. 2002. Nitric oxide burst and nitric oxide-dependent gene induction in plants. Trends Plant Sci. 40:625-631.

Innocenti, G., Pucciariello, C., Le Gleuher, M., Hopkins, J., de Stefano, M., Delledonne, M., Puppo, A., Baudouin, E., and Frendo, P. 2007. Glutathione synthesis is regulated by nitric oxide in Medicago truncatula roots. Planta 225:1597-1602.

Kondorosi, E., Redondo-Nieto, M., and Kondorosi, A. 2005. Ubiquitinmediated proteolysis. to be in the right place at the right moment during nodule development. Plant Physiol. 137:1197-1204. 
Lee, M. Y., Shin, K. H., Kim, Y. K., Suh, J. Y., Gu, Y. Y., Kim, M. R., Hur, Y. S., Son, O., Kim, J. S., Song, E., Lee, M. S., Nam, K. H., Hwang, K. H., Sung, M. K., Kim, H. J., Chun, J. Y., Park, M., Ahn, T. I., Hong, C. B., Lee, S. H., Park, H. J., Park, J. S., Verma, D. P., and Cheon, C. I. 2005. Induction of thioredoxin is required for nodule development to reduce reactive oxygen species levels in soybean roots. Plant Physiol. 139:1881-1889.

Liu, Y., Schiff, M., Marathe, R., and Dinesh-Kumar, S. P. 2002. Tobacco Rarl, EDS1 and NPR1/NIM1 like genes are required for N-mediated resistance to Tobacco mosaic virus. Plant J. 30:415-429.

Lohar, D. P., Sharopova, N., Endre, G., Penuela, S., Samac, D., Town, C., Silverstein, K. A., and VandenBosch, K. A. 2006. Transcript analysis of early nodulation events in Medicago truncatula. Plant Physiol. 140:221-234

Madsen, E. B., Madsen, L. H., Radutoiu, S., Olbryt, M., Rakwalska, M., Szczyglowski, K., Sato, S., Kaneko, T., Tabata, S., Sandal, N., and Stougaard, J. 2003. A receptor kinase gene of the LysM type is involved in legume perception of rhizobial signals. Nature 425:637-640.

Mou, Z., Fan, W., and Dong, X. 2003. Inducers of plant systemic acquired resistance regulate NPR1 function through redox changes. Cell 113:935-944.

Murgia, I., Delledonne, M., and Soave, C. 2002. Nitric oxide mediates iron-induced ferritin accumulation in Arabidopsis. Plant J. 30:521-528.

Nakatsubo, N., Kojima, H., Sakurai, K., Kikuchi, K., Nagoshi, H., Hirata, Y., Akaike, T., Maeda, H., Urano, Y., Higuchi, T., and Nagano, T. 1998. Improved nitric oxide detection using 2,3-diaminonaphthalene and its application to the evaluation of novel nitric oxide synthase inhibitors. Biol. Pharm. Bull. 21:1247-1250.

Neill, S. J., Desikan, R., Clarke, A., Hurst, R. D., and Hancock, J. T. 2002. Hydrogen peroxide and nitric oxide as signalling molecules in plants. J. Exp. Bot. 53:1237-1247.

Novatchkova, M., Budhiraja, R., Coupland, G., Eisenhaber, F., and Bachmair, A. 2004. SUMO conjugation in plants. Planta 220:1-8.

Oldroyd, G. E., Harrison, M. J., and Udvardi, M. 2005. Peace talks and trade deals. Keys to long-term harmony in legume-microbe symbioses. Plant Physiol. 137:1205-1210.

Parani, M., Rudrabhatla, S., Myers, R., Weirich, H., Smith, B., Leaman, D W., and Goldman, S. L. 2004. Microarray analysis of nitric oxide responsive transcripts in Arabidopsis. Plant Biotechnol. J. 2:359-366.

Peters, N. K., and Long, S. R. 1988. Alfalfa root exudates and compounds which promote or inhibit induction of Rhizobium meliloti nodulation genes. Plant Physiol. 88:396-400.

Pii, Y., Crimi, M., Cremonese, G., Spena, A., and Pandolfini, T. 2007. Auxin and nitric oxide control indeterminate nodule formation. BMC Plant Biol. 7:21.

Polverari, A., Molesini, B., Pezzotti, M., Buonaurio, R., Marte, M., and Delledonne, M. 2003. Nitric oxide-mediated transcriptional changes in Arabidopsis thaliana. Mol. Plant-Microbe Interact. 16:1094-1105.

Quackenbush, J., Liang, F., Holt, I., Pertea, G., and Upton, J. 2000. The TIGR gene indices: Reconstruction and representation of expressed gene sequences. Nucleic Acids Res. 28:141-145.

Radutoiu, S., Madsen, L. H., Madsen, E. B., Felle, H. H., Umehara, Y., Gronlund, M., Sato, S., Nakamura, Y., Tabata, S., Sandal, N., and Stougaard, J. 2003. Plant recognition of symbiotic bacteria requires two LysM receptor-like kinases. Nature 425:585-592.

Reuber, T. L., and Ausubel, F. M. 1996. Isolation of Arabidopsis genes that differentiate between resistance responses mediated by the RPS2 and RPM1 disease resistance genes. Plant Cell 8:241-249.

Rombauts, S., Van De Peer, Y., and Rouze, P. 2003. AFLPinSilico, simulating AFLP fingerprints. Bioinformatics 19:776-777.

Ryu, S. 2004. Phospholipid-derived signaling mediated by phospholipase A in plants. Trends Plant Sci. 9:229-235.

Salzman, R. A., Brady, J. A., Finlayson, S. A., Buchanan, C. D., Summer, E. J., Sun, F., Klein, P. E., Klein, R. R., Pratt, L. H., Cordonnier-Pratt, M.-M., and Mullet, J. E. 2005. Transcriptional profiling of sorghum induced by methyl jasmonate, salicylic acid, and aminocyclopropane car- boxylic acid reveals cooperative regulation and novel gene responses. Plant Physiol. 138:352-368.

Scharte, J., Schon, H., and Weis, E. 2005. Photosynthesis and carbohydrate metabolism in tobacco leaves during an incompatible interaction with Phytophthora nicotianae. Plant Cell Environ. 28:1421-1435.

Singh, R. J., Hogg, N., Goss, S. P., Antholine, W. E., and Kalyanaraman, B. 1999. Mechanism of superoxide dismutase/ $\mathrm{H}_{2} \mathrm{O}_{2}$-mediated nitric oxide release from S-nitrosoglutathione-role of glutamate. Arch. Biochem. Biophys. 372:8-15.

Smyth, G. K., Michaud, J., and Scott, H. S. 2005. Use of within-array replicate spots for assessing differential expression in microarray experiments. Bioinformatics 21:2067-2075.

Stamler, J. S., Singel, D. J., and Loscalzo, J. 1992. Biochemistry of nitric oxide and its redox-activated forms. Science 258:1898-1902.

Stougaard, J. 2000. Regulators and regulation of legume root nodule development. Plant Physiol. 124:531-540.

Svensson, J. T., Crosatti, C., Campoli, C., Bassi, R., Stanca, A. M., Close, T. J., and Cattivelli, L. 2006. Transcriptome analysis of cold acclimation in barley Albina and Xantha mutants. Plant Physiol. 141:257-270.

Takahashi, Y., Uehara, Y., Berberich, T., Ito, A., Saitoh, H., Miyazaki, A., Terauchi, R., and Kusano, T. 2004. A subset of hypersensitive response marker genes, including HSR203J, is the downstream target of a spermine signal transduction pathway in tobacco. Plant J. 40:586-595.

Tirichine, L., Sandal, N., Madsen, L. H., Radutoiu, S., Albrektsen, A. S., Sato, S., Asamizu, E., Tabata, S., and Stougaard, J. 2007. A gain-offunction mutation in a cytokinin receptor triggers spontaneous root nodule organogenesis. Science 315:104-107.

Torregrosa, C., Cluzet, S., Fournier, J., Huguet, T., Gamas, P., Prosperi, J. M., Esquerre-Tugaye, M. T., Dumas, B., and Jacquet, C. 2004. Cytological, genetic, and molecular analysis to characterize compatible and incompatible interactions between Medicago truncatula and Colletotrichum trifolii. Mol. Plant-Microbe Interact. 17:909-920.

Tusher, V. G., Tibshirani, R., and Chu, G. 2001. Significance analysis of microarrays applied to the ionizing radiation response. Proc. Natl. Acad. Sci. U.S.A. 98:5116-5121.

Udvardi, M. K., and Day, D. A. 1997. Metabolite transport across symbiotic membranes of legume nodules. Annu. Rev. Plant Physiol. Plant Mol. Biol. 48:493-523.

Vierstra, R. D. 2003. The ubiquitin/26S proteasome pathway, the complex last chapter in the life of many plant proteins. Trends Plant Sci. 8:135142.

Wasson, A. P., Pellerone, F. I., and Mathesius, U. 2006. Silencing the flavonoid pathway in Medicago truncatula inhibits root nodule formation and prevents auxin transport regulation by rhizobia. Plant Cell 18:1617 1629

Wisniewski, J.-P., Rathbun, E. A., Knox, J. P., and Brewin, N. J. 2000. Involvement of diamine oxidase and peroxidase in insolubilization of the extracellular matrix: Implications for pea nodule initiation by Rhizobium leguminosarum. Mol. Plant-Microbe Interact. 13:413-420.

Zago, E., Morsa, S., Dat, J. F., Alard, P., Ferrarini, A., Inze, D., Delledonne, M., and Van Breusegem, F. 2006. Nitric oxide- and hydrogen peroxideresponsive gene regulation during cell death induction in tobacco. Plant Physiol. 141:404-411.

Zaninotto, F., La Camera, S., Polverari, A., and Delledonne, M. 2006. Cross talk between reactive nitrogen and oxygen species during the hypersensitive disease resistance response. Plant Physiol. 141:379-383.

\section{AUTHOR-RECOMMENDED INTERNET RESOURCES}

National Center for Biotechnology Information website: www.ncbi.nlm.nih.gov/dbEST/dbEST_summary.html

M. truncatula Gene Index database:

compbio.dfci.harvard.edu/tgi/cgi-bin/tgi/gimain.pl?gudb=medicago

TIGR Medicago Truncatula Gene Index: www.tigr.org/tdb/tgi/mtgi

Gene Ontology Annotation database: www.ebi.ac.uk/GOA 